\title{
Failed Continuous Spinal for Hip Fracture: Case Report, Causes, Prevention and Management
}

\section{SILVA E SOUSA L, CHAN NOGUEIRA Z, SANTA BÁRBARA R, RODRIGUES VIANA I. Anesthesiology Department, Centro Hospitalar Lisboa Norte, Hospital Santa Maria}

\section{BACKGROUND:}

Continuous spinal anesthesia (CSA) allows titration of the block level, longer spinal block duration, and greater hemodynamic stability. Although regarded as a reliable regional block method, the possibility of failure has been recognized. In previous studies, the incidence of failed CSA is low.

\section{CASE REPORT:}

A 73-year-old male, ASA 3, admitted with hip fracture, proposed for surgical stabilization, was submitted to CSA. Tuohy needle was inserted at the L3-L4 intervertebral space, with freely flowing clear cerebrospinal fluid (CSF). Through an intrathecal catheter sufentanil $25 \mu \mathrm{g}$ and levobupivacaine $5 \mathrm{mg}$ were injected, followed by $1 \mathrm{~mL}$ of saline solution bolus. No evidence of sensory, motor or sympathetic block was observed in the following 15 minutes (min). Catheter localization was confirmed by CSF aspiration and glucose test. Another bolus of $7,5 \mathrm{mg}$ of levobupivacaine was injected from a new ampoule, and again no evidence of sensory, motor or sympathetic block was observed after $15 \mathrm{~min}$. Confirmation of catheter localization was made again by the same methods. In this setting, general anesthesia was instituted. At the end of the surgical procedure, 60 min later, it was still possible to aspirate CSF from the catheter, though without any evidence of anesthetic or analgesic effect.

\section{DISCUSSION}

Based on repeated confirmation of catheter localization, lumbar puncture and catheter misplacement have been ruled out. Factors affecting the spread of local anesthetics solution through CSF were considered as the main possible causes in this case. Besides obvious anatomical abnormalities, which were not documented in our patient, septae formed by ligaments, spinal stenosis or congenital arachnoid cysts were considered as the most likely etiologies. Although rare, local acidosis and sodium channels mutation can be considered as well as a cause of CSA failure.

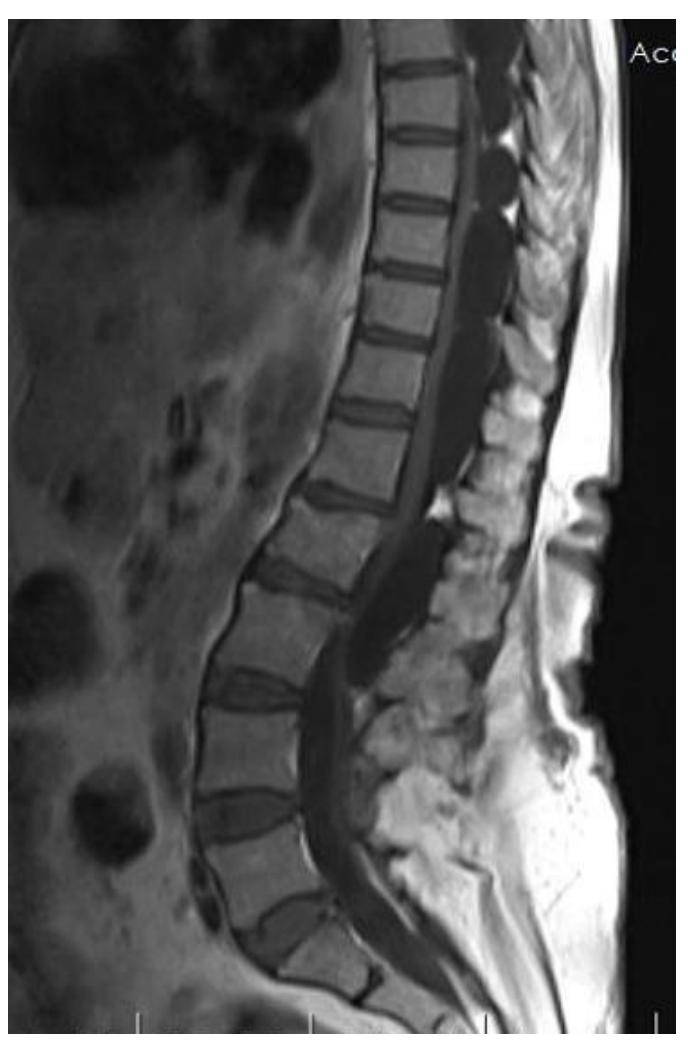

Figure 1

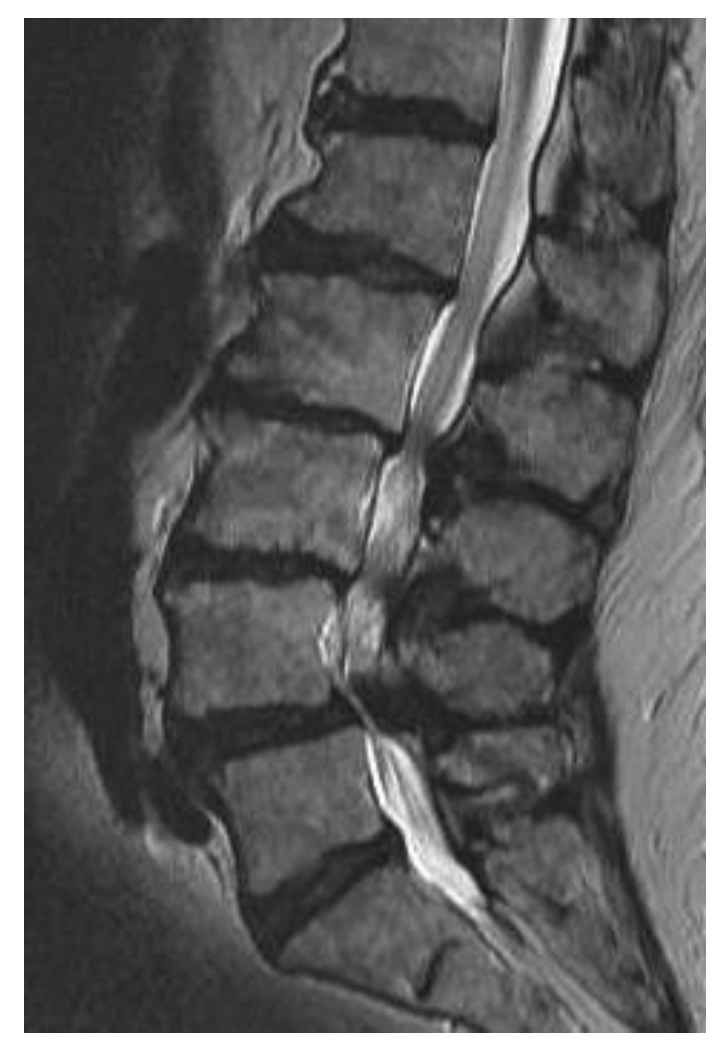

Figure 2

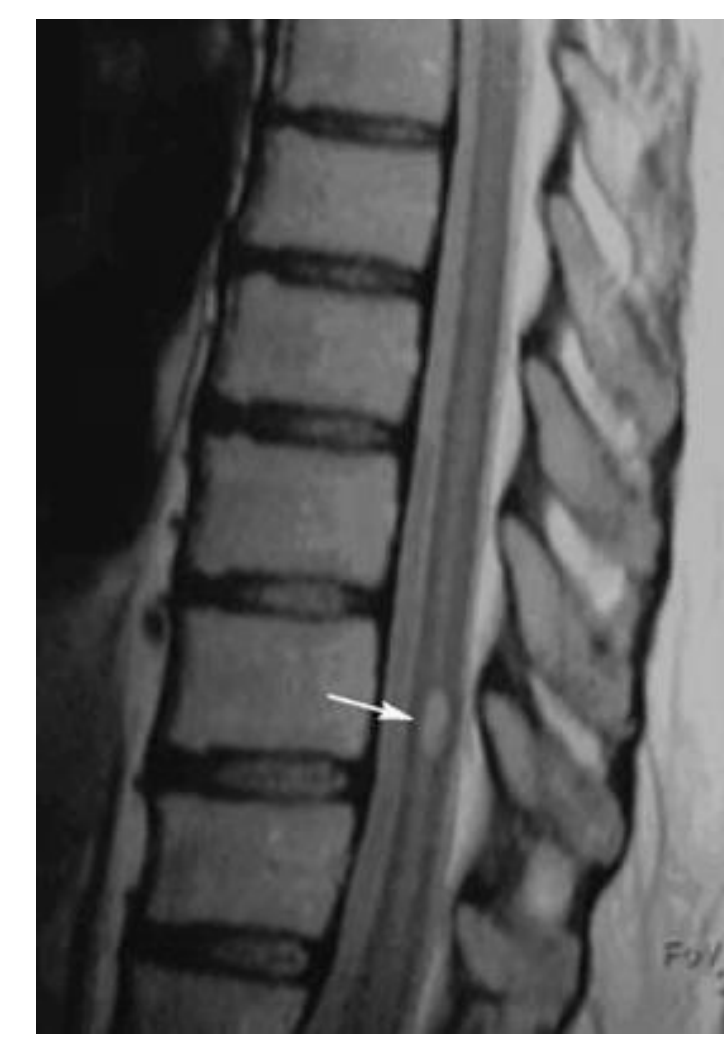

Figure 3
Figure 1. Subaracnoid septae

Figure 2. Spinal stenosis

Figure 3. Arachnoid cyst

\section{LEARNING POINTS:}

Although CSA is considered a highly reliable technique, in seldom cases this technique can result in an anesthetic failure

\section{REFERENCES:}

Moore JM. CSA. Am J Ther. 2009 Jul-Aug;16(4):289-94; Kung CC1, Lin SY, Tang CS, Wu TJ, Sun WZ. Clinical study of failure in CSA with bupivacaine. Kaohsiung J Med Sci. 1998 Aug;14(8):486-91; Figure 1. Pallewatte A. Multiple spinal arachnoid cysts. Radiopaedia. Figure 2. Fairbank J. and Mallen C. Cauda equina syndrome: implications for primary care. Br J Gen Pract 2014; 64 (619): 67-68. Hughes G. et all. A review of spinal arachnoid cysts Cleveland Clinic Journal of Medicine. 2008 April;75(4):311-315 